\title{
Article
}

\section{Investigating hyper-vigilance for social threat of lonely children}

Qualter, Pamela, Rotenberg, K J, Barrett, Louise, Henzi, Peter, Barlow, Alexandra, Stylianou, Maria and Harris, Rebecca

Available at http://clok.uclan.ac.uk/4847/

Qualter, Pamela, Rotenberg, KJ, Barrett, Louise, Henzi, Peter, Barlow, Alexandra, Stylianou, Maria and Harris, Rebecca ORCID: 0000-0003-43262425 (2013) Investigating hyper-vigilance for social threat of lonely children. Journal of Abnormal Child Psychology, 41 (2). pp. 325-338. ISSN 0091-0627

It is advisable to refer to the publisher's version if you intend to cite from the work. http://dx.doi.org/10.1007/s10802-012-9676-x

For more information about UCLan's research in this area go to http://www.uclan.ac.uk/researchgroups/ and search for <name of research Group>.

For information about Research generally at UCLan please go to http://www.uclan.ac.uk/research/

All outputs in CLoK are protected by Intellectual Property Rights law, including Copyright law. Copyright, IPR and Moral Rights for the works on this site are retained by the individual authors and/or other copyright owners. Terms and conditions for use of this material are defined in the policies page. 
Running Head: LONELINESS AND HYPERVIGILANCE TO SOCIAL THREAT

1

Investigating Hypervigilance for Social Threat of Lonely Children

Article

Other: Qualter, P., Rotenberg, K. J. Barrett, L., Henzi, P, et al., (2012). Investigating Hypervigilance for Social Threat of Lonely Children. Journal of Abnormal Child Psychology. iFirst, Print ISSN: 0091-0627; Online ISSN: 1573-2835;

doi:10.1007/s10802-012-9676-x Available

at: $\underline{\text { http://link.springer.com/article/10.1007/s10802-012-9676-X }}$

It is advisable to refer to the publisher's version if you intend to cite from the work.

To link to this article $\underline{\text { http://link.springer.com/article/10.1007/s10802-012-9676-x }}$ 
Running Head: LONELINESS AND HYPERVIGILANCE TO SOCIAL THREAT Investigating Hypervigilance for Social Threat of Lonely Children

Pamela Qualter ${ }^{1}$, Ken Rotenberg ${ }^{2}$, Louise Barrett ${ }^{3}$, Peter Henzi ${ }^{3}$, Alexandra Barlow ${ }^{4}$, Maria Stylianou ${ }^{5}$, \& Rebecca A. Harris ${ }^{1}$

${ }^{1}$ School of Psychology, University of Central Lancashire, Preston, Lancashire, UK

${ }^{2}$ Research Institute for Life Sciences, Keele University, Keele, Staffordshire, UK

${ }^{3}$ Dept. of Psychology, University of Lethridge, Lethbridge, Alberta, Canada

${ }^{4}$ School of Education, University of Manchester, Manchester, UK

${ }^{5}$ Dept. of Psychology, Neapolis University, 2 Pafos, Cyprus

Acknowledgements: Studies 2 and 3 were supported by a grant from the Economic and Social Research Council (Grant RES-000-22-1802) awarded to the first author. We wish to thank the following students who helped with data collection: Fiona Burke, Fiona Hamilton, Vicky Leaning, Joelle Moore, Emily Northrop, and Sarah Rennison.

*Reprint requests to Pamela Qualter, School of Psychology, University of Central Lancashire, UK, PR1 2HE: Tel: (+044) 01772 893877; E-mail: PQualter@uclan.ac.uk 
Running Head: LONELINESS AND HYPERVIGILANCE TO SOCIAL THREAT

\begin{abstract}
This series of studies is the first to examine hypervigilance for social threat among lonely children and the first to establish this link using eye-tracking technology. Hypervigilance for social threat was operationalised as hostility to ambiguously motivated social exclusion in a variation of the hostile attribution paradigm (Study 1), scores on the Children's RejectionSensitivity Questionnaire (Study 2), and visual attention to socially threatening stimuli (Study 3). The participants were 185 children (11 years -7 months to 12 years -6 months), 248 children (9 years -4 months to 11 years -8 months) and 147 children (8 years -10 months to 12 years - 10 months) in the three studies, respectively. Regression analyses showed that, with depressive symptoms covaried, there were quadratic relations between loneliness and these different measures of hypervigilance to social threat. As hypothesized, only children in the upper range of loneliness demonstrated elevated hostility to ambiguously motivated social exclusion, higher scores on the rejection sensitivity questionnaire, and disengagement difficulties when viewing socially threatening stimuli. We found that very lonely children are hypersensitive to social threat.
\end{abstract}

Key words: Loneliness; Children; Hypervigilance; Social Threat; Rejection; Hypersensitivity, Rejection-sensitivity; Eye movement; Attentional bias. 
Running Head: LONELINESS AND HYPERVIGILANCE TO SOCIAL THREAT

Investigating Hypervigilance for Social Threat of Lonely Children

Researchers have examined the social information processing biases that serve to maintain loneliness. One such bias is conceptualized as the 'hypervigilance for social threat hypothesis’ (HSTH), where it is argued that rejection sensitivity contributes to behavioral deficiencies (e.g., withdrawal) that undermine the opportunities to develop and maintain positive social relationships (Cacioppo \& Hawkley, 2009). Several studies provide support for the HSTH in adults (Jones \& Carver, 1991; Jones, Freemon \& Goswick, 1981; Sloan \& Solano, 1984), but there has been little work on this in children. Confirming the HSTH during childhood is important because it would indicate that this form of social information bias is evident during development and, therefore, a potential contributor to the persistence of loneliness from childhood through to adulthood, which itself predicts mental and physical health.

\section{Loneliness and social information processing biases}

Loneliness is an unpleasant state that arises from a discrepancy between the interpersonal relationships people want to have, and those they perceive they currently have (Peplau \& Perlman, 1982). Loneliness is not linked to the number of friends that a person has (Young, 1982; Qualter \& Munn, 2005). It is a prevalent problem in children, adolescents and adults (Cacioppo \& Patrick, 2008; Rotenberg \& Hymel, 1999), and is acknowledged in the Diagnostic and Statistical Manual for Mental Disorders (DSM-IV-TR: American Psychiatric Association, 2000) because it often causes significant distress and/or intensifies mental disorders or conditions (Heinrich \& Gullone, 2006). It is argued that loneliness is a common emotion that serves to promote reconnection with others (Baumeister \& Leary, 1995). However, for some people, loneliness is a persistent feeling (Hawkley \& Cacioppo, 2010), which Hawkley et al., (2003) argue is an outcome of faulty cognitions related to social threat.

Cacioppo and Hawkley’s (2009) model of loneliness highlights that social information processing biases serve to maintain loneliness. This 'Hypervigilance to Social Threat Hypothesis’ (HSTH) proposes that feelings of loneliness are associated with hypervigilance for social threats; these cognitive biases may be in place before lonely feelings, but their presence impacts behaviour such that there are decreased opportunities to develop and maintain positive 
Running Head: LONELINESS AND HYPERVIGILANCE TO SOCIAL THREAT

friendships. Empirical studies with adults show specific processing bias for loneliness linked directly to the person's fear of being rejected and isolated from others (Jones \& Carver, 1991; Jones, et al., 1981; Sloan \& Solano, 1984); it is not the same as social anxiety (Jones, Rose, \& Russell, 1990).

Being lonely certainly influences how people perceive their social world (Cacioppo \& Hawkley, 2009). For example, despite their own perceptions of being rejected, empirical work shows that lonely adults are not overly rejected by others (Jones, 1990; Jones \& Carver, 1991; Jones et al., 1981; Jones, Sansone, \& Helm, 1983; Sloan \& Solano, 1984). And, although peer rejection has been shown to be associated with loneliness during childhood (Asher, Parkhurst, Hymel, \& Williams, 1990; Boivin, Hymel and Bukowski, 1995), there is some indication that perceived peer rejection rather than actual rejection plays a crucial role in these associations, with a large proportion of lonely children being well liked by their peers (Qualter \& Munn, 2002, 2005). Given this, it is surprising that there has been no concerted focus on the (HSTH) cognitions related to loneliness the childhood.

Additional support for HSTH comes from research showing that lonely adults also feel more threatened in social encounters and worry more about being disliked by others (Cacioppo, Ernst, et al., 2000; Duck, Pond \& Leatham, 1994; Jones et al., 1983; Jones et al., 1981). Amongst adolescents, loneliness is related to reports of interpersonal stress and fears of being rejected by peers (Doane \& Adam, 2010). Lonely adults and children also make more selfderogatory attributions compared to non-lonely people, seeing themselves as less likable than their peers (Snodgrass, 1987; Qualter \& Munn, 2002). Thus, there is evidence of the cognitive biases that form part of the HSTH for loneliness in adults; certain cognitive biases are also evident in childhood.

As further support for HSTH, findings from Cacioppo, Norris, et al., (2009) suggest that lonely adults preferentially attend to negative social information: they had fewer neural responses to pleasant social stimuli, with heightened neural activation during the viewing of unpleasant social pictures.

Almost all of what we know about the HSTH for loneliness comes from research on 
Running Head: LONELINESS AND HYPERVIGILANCE TO SOCIAL THREAT

adults. But, empirical research examining the HSTH in childhood/early adolescence is important for two reasons. First, given that cognitive processes develop throughout childhood and adolescence based on neurological changes during this time (Luna, Garver, Urban, Lazar, \& Sweeney, 2004), we might expect lonely children to show a different pattern of hypervigilance to social threat compared to adults. For example, compared to adults, children display inferior abilities to consciously relocate attention (Pearson \& Lane, 1991; Anderson, Anderson, Northam, Jacobs, \& Catroppa, 2001), suggesting that lonely children may be more hypervigilant to social threat than lonely adults and/or show problems of disengagement from (possible) social threats. Given that children do not have mature attentional abilities, findings from the adult literature on HSTH should not be generalised to children.

Second, loneliness in childhood leads to poor mental and physical health in later adolescence (Jobe-Shields et al., 2011; Jones et al., 2011; Qualter et al, 2010; Qualter et al., in press), but currently, our capacity to develop appropriate intervention strategies for lonely children is limited because we do not know what mechanisms are involved in the maintenance of loneliness. Cacioppo and Hawkley (2009) implicate hypervigilance to social threat as a mechanism by which loneliness is maintained during development, but these cognitive biases have not been investigated thoroughly amongst child samples.

In the current series of studies, our aim was to investigate the HSTH for loneliness in childhood. We examine HSTH for loneliness in three separate samples of children using different methodologies; similarity in the findings across the three studies would mean any effects are not an artifact of one particular method and that there is a distinctive pattern of social information processes associated with loneliness in childhood. In our work, we overcame several limitations of previous work on HSTH with adults.

\section{Limitations of previous work on HSTH}

There are several major limitations in the method of testing HSTH for loneliness. For example, some evidence reported to support the HSTH for loneliness assessed cognitive processing of experimentally rejected adults rather than those who were lonely (Gardner, Pickett, \& Brewer, 2000; Baumeister, DeWall, Ciarocco, \& Twenge, 2005). Given that lonely 
Running Head: LONELINESS AND HYPERVIGILANCE TO SOCIAL THREAT

people are not necessarily rejected (Qualter \& Munn, 2002, 2005; Young, 1982), it is important to investigate the cognitive biases of lonely people, where loneliness is measured using standardized loneliness questionnaires.

It is also important to ensure that the loneliness measures used are 'pure' measures of that construct. Measures used in the previous childhood studies include the Illinois Loneliness and Social Satisfaction scale (ILSS; Asher, Hymel, \& Renshaw, 1984) and the Loneliness and Aloneness Scale for Children and Adolescents (LACA; Marcoen, Goossens, \& Caes, 1987). The ILSS and the LACA include items assessing dissatisfaction with peer relationships and anticipated rejection by peers. The inclusion of such items in research would result in the overlap in content between loneliness and the sensitivity to rejection measures and thus result in correlations between them. Thus, in our three studies, loneliness was assessed by "pure" measures of the construct (Ladd, Kochenderfer, \& Coleman, 1996, 1997) that comprise children's ratings of their affective experiences of loneliness. These pure measures were derived from the broader ILSS and LACA.

A related issue is the need to examine quadratic relations between loneliness and measures of sensitivity to social threat. Cacioppo et al (2006) note that research examining the HSTH for loneliness is limited because it analyses linear correlations/regression; it may be the case that sensitivity to social threat characterizes only those who are very lonely. There is an assumption underlying previous work on HSTH that loneliness exists on a continuum of severity, where non-loneliness and milder states of loneliness form a continuum with severe loneliness, differing only in the severity and persistence of the symptomatology. But, Cacioppo et al point out that loneliness may not work in this way: severe loneliness may be qualitatively different from milder forms of loneliness and non-loneliness. Evidence for this discontinuity perspective would be the distinctiveness in social threat response between the severe lonely group and milder lonely or non-lonely groups. Guided by this approach, we examined whether the relation between loneliness and hypervigilance to social threat is curvilinear, specifically quadratic, and thus discontinuous. The research specifically examined whether there is a point 
Running Head: LONELINESS AND HYPERVIGILANCE TO SOCIAL THREAT

on the child loneliness scale where there is an accompanying change in behaviour, such that there is elevated vigilance to social threat.

Another important consideration is the association between loneliness and depression. These constructs are strongly associated, although they are different (see Lasgaard, Goossens, \& Elklit, 2010; Nangle et al., 2003; Qualter et al., 2010). Furthermore, there is evidence that depressive symptoms are associated with both peer rejection (e.g., Boivin, Poulin, \& Vitaro, 1994), and sensitivity to rejection (Dineen, \& Hadwin, 2004; Quiggle et al., 1992).

Consequently, depressive symptoms could account for the observed relations between loneliness and measures of hypervigilance for social threat in adults. In the current series of studies, depressive symptoms were entered as covariants in the analyses to examine whether the patterns associated with loneliness are explained by depression and negative person perception.

\section{The current series of studies}

Our studies use different methods to investigate the HSTH in lonely children. Convergence of findings for the studies using different samples and different methodologies would provide clear evidence that loneliness is associated with hypervigilance to social threat in childhood. In Study 1, a variation of the hostile attribution paradigm was employed. That study was guided by the assumption that social exclusion is a prototypical form of peer rejection (see Hawker \& Boulton, 2000) that functions as peer provocation for children and, thus, elicits retaliatory aggression from them. In that context, children's tendency to attribute hostile intention and/or retaliatory aggression to ambiguously motivated social exclusion was regarded as indicative of hypervigilance for social threat: a hostile attribution bias to a given type of provocation.

It was expected on the basis of the HSTH that lonely children would be more likely to attribute hostile intentions and/or report greater retaliatory aggression (hostility overall) to ambiguously motivated social exclusion by peers than would their non-lonely counterparts. The HSTH necessitates that lonely children's attribution of hostile intention and/or retaliatory aggression to ambiguously motivated social exclusion should be distinctive from the patterns they show to intentionally motivated social and other forms of peer provocation. If these 
Running Head: LONELINESS AND HYPERVIGILANCE TO SOCIAL THREAT

expectations were confirmed, they would undermine negative social perception as an account of the findings.

In Study 2, we used the rejection sensitivity paradigm developed by Downey et al. (1998) to examine the HSTH for lonely children. Downey et al. argue that those who experience early parental rejection develop 'rejection expectations' that are used in ambiguous situations where rejection may be possible. The argument is that when activated, these defensive rejection expectations lead to a hypervigilance for social threat. In line with Cacioppo and Hawkley's (2009) HSTH for loneliness model, this tendency to expect, perceive and overreact to possible rejection may stop the child from engaging with others positively, and minimize their opportunities to develop social skills and positive relationships, contributing to feelings of loneliness (Downey, Freitas, et al., 1998; Levy, Ayduk, \& Downey, 2002; London, Downey, Bonica, \& Paltin, 2007). Rejection sensitivity in childhood - as defined by this model - is measured by the Children's Rejection Sensitivity Questionnaire (CRSQ: Downey, Lebolt, et al., 1998).

Based on the HSTH, it was expected in Study 2 that loneliness would be associated with scores on CRSQ. The latter was generalized sensitivity to rejection (see Sandstrom, Cillessen, \& Eisenhower, 2003) because it was anticipated that loneliness could be potentially manifested in anxiety of expected rejection, anger towards expected rejection, and anticipated rejection (London et al., 2007).

In Study 3, we investigated whether lonely children showed attentional biases to social threat stimuli shown in dynamic social scenes. Using eye-tracking methodology, we obtained a continuous measurement of selective attention to determine the exact pattern of attention deployment characteristic of lonely children. We expected to find patterns of attention deployment that were consistent with hypervigilant for social threat. Based on empirical examination of response to threat stimuli, hypervigilence could be demonstrated by (1) an initial vigilance toward socially threatening stimuli that lasts a few seconds, followed by an avoidance of that same stimuli (In-Albon, Kossowsky, \& Schneider, 2010; Lange et al., 2011) or (2) an inability to disengage from the socially threatening stimuli (Buckner, Maner, \& Schmidt, 2010). 
Running Head: LONELINESS AND HYPERVIGILANCE TO SOCIAL THREAT

Because this is the first study to investigate attentional biases to threatening stimuli amongst lonely people, we did not hypothesize the exact effect of the HSTH for loneliness on attention deployment. We simply asked (a) when viewing socially threatening stimuli, is the attention deployment strategy of lonely children different to that of non-lonely children?, and (b) does the attention deployment strategy used by lonely children 'fit' what we would expect from people hypervigilant to social threat? HSTH would suggest that biases in eye-gaze are likely as preexisting expectations for social threat are readily triggered and used to understand social interaction cues and potential dangers (Cacioppo \& Hawkley, 2009), but the model does not specify the type of gaze deployment expected and no previous investigations have been published to our knowledge. Study 3 was the first attempt to examine motivated attention deployment strategies of the HSTH for loneliness using eye-tracker technology.

Together, these studies investigated the HSTH for loneliness in three independent samples of children. In Studies 1 and 2, we examined threat-related cognitions. In Study 3, we examined the attention deployment strategies used by lonely children when viewing socially threatening stimuli. The studies determined whether there was a curvilinear, specifically quadratic, relation between loneliness and the measures of hypervigilance for social threat as an attempt to understand whether loneliness in childhood is discontinuous or not. Also, we covaried depressive symptoms, thus distinguishing the patterns attributable to loneliness from those attributable to depression and negative social perception.

\section{Study 1}

\section{Method}

Participants. The participants were 185 children (102 boys and 83 girls) enrolled in year 7 of a high school in the United Kingdom. The high school served a large range of regions varying from low to high socio-economic background as assessed by the Government's Index of Deprivation (http://www.imd.communities.gov.uk/). The mean age was 12 years -2 months ( $\mathrm{SD}=3$ months) and ranged from 11 years -7 months to 12 years -6 months. Active consent had been obtained by the parents/guardians of the children for participation.

Measures. 
Running Head: LONELINESS AND HYPERVIGILANCE TO SOCIAL THREAT

Stimuli: The vignettes. Dodge’s (1980) vignettes were used to depict 2 Levels of Motivation (hostile or ambiguous) by 3 Types (physical, verbal or social exclusion) of peer provocation. The names of the characters in the vignettes and the spelling were adjusted for testing children residing in the UK. Also, two sets of vignettes were constructed: one portraying girls and other portraying boys. Participants were presented with the vignettes portraying the same gender as them.

The following are examples of the vignettes presented to girls. Physical provocation was portrayed as "Whilst the children were eating in the lunch room, Rachael poured (hostilely motivated) or spilt her (ambiguously motivated) coke over Sally.” Verbal provocation was portrayed as "Alice failed the spelling test and Emily laughed out loud and said 'better luck next time stupid' (hostilely motivated) or 'better luck next time’ (ambiguously motivated). Social exclusion was portrayed as "In class the children were asked to get into pairs by their teacher; Emily said to Stacey ‘I don’t want to work with you’ (hostilely motivated) or ‘sorry, I already have a partner' (ambiguously motivated).

Following the measures by Dodge (1980), the participant was required to imagine that she/he was the victim and report what he/she thinks and how he/she would behave. The participant's first task was to write-down in his or her own words what happened in the story (the vignette). Based on content analyses of the answers, it was found that all participants showed a basic accurate comprehension of the vignettes. The participant was posed the following two questions: (1) "if you were the victim (by name) how likely would it be for you to attempt to harm the perpetrator either physically or emotionally? Emotional means hurting someone’s feelings” (retaliation) and (2) “To what extent do you think that the perpetrator (by name) meant to harm the victim either physically, verbally, or emotionally?” (attribution of hostile intention). Judgments were made on a five-point scale ranging from 1 - very likely to 5 very unlikely. Hostility was calculated by summing retaliation scores and attributed hostile intention scores. For analyses purposes, the direction of the judgments was reversed such that higher scores on the measures were indicative of greater retaliation, attribution of hostile intentions, and hostility. Each measure demonstrated acceptable internal consistency across the 
Running Head: LONELINESS AND HYPERVIGILANCE TO SOCIAL THREAT

vignettes, $\alpha=.79, \alpha=.84$, and $\alpha=.85$ for retaliation, hostile intention, and hostility respectively.

Loneliness. This was assessed by a four-item "pure" measure derived from Asher, Hymel, and Renshaw's (1984) Loneliness and Social Satisfaction scale. This pure loneliness scale has been used by Ladd and his colleagues (i.e., Ladd , Kochenderfer, \& Coleman, 1996, 1997) in order to avoid a confound with social satisfaction. The items judged on 5-point scales were "I am lonely," "I feel alone." "I feel left out of things," and "I have no one to talk to". Higher scores on the scale were indicative of greater loneliness. In the current study, this scale demonstrated acceptable internal consistency, $\alpha=.86$.

Depressive symptoms. This was assessed by the 10-item short-form of the Child Depression Inventory (CDI). Each item consists of three choices $(0,1,2)$. Scores range from 0 to 20 with higher scores corresponding to higher depressive symptoms. The short-form of the CDI scale has been found to display acceptable internal consistency, reliability, and validity (Kovacs \& Beck, 1977; Kovacs, 1992). In the current study, this scale demonstrated acceptable internal consistency, $\alpha=.91$. The CDI was used in the study by Quiggle et al. (1992), which demonstrated the association between depressive symptoms and the hostility attribution bias.

\section{Procedure.}

Testing was completed in classrooms with participants in small groups ranging from 3 to 5. They provided their answers independently. Participants were presented the six scenarios on audiotape. The participants were told that this was not a test and that they were to give their own honest answers. The participants were assured that their answers would be confidential and their participation anonymous.

\section{Results}

Effectiveness of the manipulation of the hostile intention of the peer provocation. The attribution of hostile intentions to the perpetrator were subjected to a 2 Sex of Child (Male versus Female) x 3 Types of Provocation (Physical, Verbal, Social Exclusion) x 2 Type of Motivation (Hostile versus Ambiguous) ANOVA with repeated measures on the latter two variables. The ANOVA yielded effects of Type of Motivation, $F(1,336)=462.42 ., p=.001$ that 
Running Head: LONELINESS AND HYPERVIGILANCE TO SOCIAL THREAT was qualified by Type of Provocation, $F(2,336)=5.84, p=.003$. As expected, greater attribution of hostile intentions were made to hostilely motivated provocation than to ambiguously motivated provocation for: (a) physical provocation ( $M s=3.93$ and 2.64, respectively), (b) verbal provocation ( $M s=4.27$ and 2.99, respectively) and (c) social exclusion (Ms $=3.91$ and 2.17, respectively). A posteriori comparisons showed that the interaction was attributable to the lower attribution of hostile intentions to ambiguously motivated verbal provocation than to ambiguously motivated social exclusion $(p<.05)$. Nevertheless, as expected, the attribution of hostile intentions to ambiguously motivated provocation fell close to the middle point of the scale and the attribution of hostile intentions to the hostilely motivated provocation fell close to the high range of the scale. The ANOVA did not yield effects or approach significant effects for gender. The findings yielded support for the conclusion that the intentions of the perpetrator in the vignettes were varied in the desired fashion for girls and boys.

Partial correlations among the types of provocation and loneliness separately for attribution of hostile intentions, retaliation, and hostility. The partial correlations for the attribution of hostile intentions and retaliation are shown in Table 1 and for hostility in Table 2. Depressive symptoms were correlated with loneliness, $r(183)=.58, p=.001$ and were statistically controlled. It should be highlighted that the partial correlations only marginally deviated $(-.06$ to +.06$)$ from the simple correlations in these analyses. In the text, the correlations are positive unless reported to the contrary.

Consistent with the HSTH, loneliness was correlated with ambiguous social exclusion provocation on each of the three measures: attribution of hostile intentions, retaliation, and hostility. Support for HSTH depended on the observation that lonely children would display greater hostility (as assessed by the three measures) towards ambiguous motivated social exclusion than hostilely intended social exclusion. In support of that hypothesis, the correlation between loneliness and attribution of hostile intentions, retaliation, and hostility to ambiguously motivated social exclusion provocation were statistically different from those to hostilely intended social exclusion provocation as tested by Fischer's z transformation at $p<.05$. Finally, 
Running Head: LONELINESS AND HYPERVIGILANCE TO SOCIAL THREAT

the ruling out of general negative social perceptions as an account of the hypothesized findings depended on whether the hostility shown by lonely children towards ambiguous motivated social exclusion was different from the hostility they showed towards peer provocateur of ambiguously or hostilely intended physical or verbal peer provocation. This was confirmed: the correlations between loneliness and attribution of hostile intentions, retaliation, and hostility to ambiguously motivated social exclusion provocation were statistically different from the correlations between loneliness and the three measures for the other types of provocations as tested by Fischer's z transformation at $p<.05$.

There was evidence that loneliness was negatively associated with the three measures for types of peer provocation other than social exclusion. Loneliness was negatively correlated with (1) retaliation and hostility, to hostilely motivated physical provocation, and (2) the attribution of hostile intentions and retaliation for hostilely motivated verbal provocation.

Linearity of the relation with hostility. The relation between loneliness and the hostility measure to the ambiguously motivated social exclusion provocation was subjected to a curvilinear analysis (see Cohen et al., 2003) using the residual of loneliness as the IV (thus, controlling for depression). The curvilinear effects comprise those with the linear effects statistically controlled. The analysis yielded a non-significant linear relation, $\beta=-.23$, but yielded a quadratic relation, $\beta=.39, p=.039$. There was an absence of a relation between loneliness and hostility to the ambiguously motivated social exclusion provocation for low loneliness ranging from 0 to 7 on the scale. For scores greater than 7 , though, there was a positive exponential relation between the two measures. The findings show that elevated levels of hostility to ambiguously motivated social exclusion provocation are shown primarily by highly lonely participants. A similar quadratic relation was found for the attribution of hostile intentions, $\beta=.42, p=.039$, and for retaliation, $\beta=.33, p=.087$.

In order to examine the curvilinear pattern further, participants were divided into a lowmedium lonely group with scores below 7 (135 participants) and high lonely group (50 participants) with scores above 7 . The score of 7 demarcates the upper quartile (25\%) of the loneliness scores. The hostility measure scores to social exclusion provocation were subjected to 
Running Head: LONELINESS AND HYPERVIGILANCE TO SOCIAL THREAT

a 2 Levels of Loneliness (Low-Medium versus High) x 2 Levels of Motivation of Provocation

(Hostile versus Ambiguous) ANOVA with repeated measures on the latter variable. As in

previous analyses, depressive symptoms were used as a covariate. The ANOVA yielded a main effect of Levels of Motivation of Provocation, $F(1,182)=55.30, p=.001$ but that was qualified by a two-way interaction, $F(1,182)=4.07, p=.034$. Consistent with the HSTH, high lonely participants showed greater hostility to ambiguously motivated social exclusion provocation than did the low-medium lonely participants ( $M=4.64$ and $M=3.86$, respectively). There were no appreciable differences between the low-medium and high levels of loneliness for hostility to the hostilely motivated social exclusion provocation ( $M=6.86$ and $M=6.80$, respectively). Also, each group showed greater hostility to the hostilely motivated than to the ambiguously motivated social exclusion provocation (all $p s<.05$ ).

\section{Conclusion}

Consistent with HSTH, loneliness was positively associated with the attribution of hostile intentions, retaliation, and hostility to ambiguously motivated social exclusion provocation when depressive symptoms were statistically controlled for. Those associations were different from those found between loneliness and the measures for hostilely motivated social exclusion and other forms of peer provocation. These findings yield support for the cue distortion principle and further help to rule out general negative social perceptions as an account of the findings. As evidence for severity, a quadratic relation was found in which only very lonely children - those in the upper quartile - showed elevated hostility to ambiguously motivated social exclusion provocation. Also, it was found that loneliness was negatively correlated with the measures of hostility towards hostilely intended physical and verbal provocation.

Study 1 provides support for the HSTH for loneliness in childhood as we found that lonely children were more likely to attribute hostile intentions and report greater retaliatory aggression to ambiguously motivated social exclusion by peers than were their non-lonely counterparts. In Study 2, we further examine the HSTH for loneliness by investigating whether lonely children have a tendency to expect, perceive and overreact to possible rejection.

\section{Study 2}


Running Head: LONELINESS AND HYPERVIGILANCE TO SOCIAL THREAT

\section{Method}

Participants. The sampling frame was developed to ensure that children were chosen from six schools in the North West of England that were reasonably representative of schools in different areas of the UK as determined by the Government Index of Multiple Deprivation (http://www.imd.communities.gov.uk/). The participants were 248 children (139 boys and 109 girls) enrolled in Years 5 and 6 in six primary schools in the North West of England, UK. The mean age of participants was 10 years 3 months (age range $=9$ years -4 months to 11 years -4 months, SD = 9 months). Active consent had been obtained by the parents/guardians of the children for participation.

\section{Measures.}

Generalized rejection sensitivity. The Children's Rejection Sensitivity Questionnaire (CRSQ: Downey, Lebolt, et al., 1998) was employed. It presents children with twelve peerrelated vignettes in which the possibility of rejection exists. In the current study, these were presented to the children on paper. As an example, in one of the vignettes, children are asked to imagine that they want to buy a present for someone who is important to them but they do not have enough money. The child is asked to imagine asking a fellow classmate for some money, to which the classmate agrees and they decided to meet after class. The children are then asked how they feel waiting for their classmate to bring them the money.

For each vignette, children are first asked to indicate the degree of anxious anticipatory affect they would experience in that situation (e.g. How nervous would you feel about whether or not the classmate will show up?), using a six point likert scale ranging from 1 (not nervous) to 6 (very nervous). They also indicate how angry they would feel, using the 6-point scale. Then, the children indicate the likelihood that the other person would respond with acceptance or rejection (e.g. Do you think the kid will show up to give you the money?) choosing between three categories (yes, no or maybe). We scored the measure according to Sandstrom et al. (2003). This scoring method provides a generalized rejection sensitivity score that was computed by averaging the 36 appraisal ratings for each child. The internal consistency of this composite score was acceptable, $\alpha=.82$. 
Running Head: LONELINESS AND HYPERVIGILANCE TO SOCIAL THREAT

Loneliness. This was assessed using the 12-item Peer subscale of the Loneliness and Aloneness Scale for Children and Adolescents (LACA: Marcoen, Goossens, \& Caes, 1987). A pure scale of loneliness was constructed that was composed of the items: 'I feel cut-off from other people', 'I feel alone at school', 'I feel left out by my friends', and 'I have no best friend that I can tell everything to'. Children were required to use a 4-point rating scale, ranging from 1 (never) to 4 (often) to answer questions related to their peer experiences. Mean loneliness scores were used (range 1-4), with higher scores indicating higher loneliness. In the current study, the scale demonstrated acceptable internal consistency, $\alpha=.76$. Because the pure loneliness score was positively skewed, it was subjected to a log10 transformation in order to normalize its distribution.

Depressive symptoms. As in Study 1, the 10-item Children's Depression Inventory (CDI: Kovacs, 1992) was used to assess depressive symptoms. Internal consistency for the current sample was acceptable, $\alpha=.89$.

\section{Procedure.}

Although testing was completed in classrooms with participants in groups of 4-6 pupils, they provided their answers independently. Completion of the loneliness and depression tasks was counterbalanced so that they followed the rejection-sensitivity scale in some sessions and not others. Children were told that this was not a test and that they were to give their own honest answers. They were also told that their answers were confidential.

\section{Results}

Descriptive information and Correlations among the measures. Mean scores and standard deviations for the variables were as follows: loneliness $=1.94(\mathrm{SD}=.99)$, depression $=$ 5.15, $\mathrm{SD}=4.84$, generalized rejection-sensitivity $=3.29(\mathrm{SD}=.39)$. As expected, loneliness was positively correlated with depressive symptoms, $r=.44, p<.001$. Also, depressive symptoms were positively correlated with rejection-sensitivity, $r=.12, p=.048$. Consistent with the HSTH, loneliness was positively correlated with rejection-sensitivity without depressive symptoms statistically controlled, $r=.29, p=.001$, and with depressive symptoms statistically controlled, $r=.16, p=.005$. 
Running Head: LONELINESS AND HYPERVIGILANCE TO SOCIAL THREAT

The relation between loneliness and rejection-sensitivity scores. The residual of loneliness was created by regressing depression onto loneliness. This enabled depression to be controlled in all analyses. The relation between the residual loneliness score and the generalized rejection sensitivity score was subjected to a curvilinear analysis. Analysis yielded a significant linear relation, $\beta=.72, p=.010$. Controlling for this the linear effects, analyses revealed a quadratic relation, $\beta=.89, p=.009$. There was an overall positive relation between loneliness and rejection-sensitivity scores.

In order to examine the curvilinear pattern further, participants were divided into a lowmedium lonely group with mean scores below or equal to 3 on the pure loneliness scale (219 participants) and high lonely group (29 participants) with scores above 3 . The score of 3 demarcates the upper quartile of the loneliness scores. A t-test comparing the two groups yielded significance, $t=5.22, p=.001, d=1.03$. As expected, the high lonely group showed significantly greater rejection sensitivity $(M=3.75)$ than did the low-medium lonely group $(M=$ $1.11)$

\section{Conclusion}

The findings yielded support for HSTH for loneliness showing the expected curvilinear relation between loneliness and generalized sensitivity to rejection. As evidence that severity of loneliness is important we found that only children within the upper quadrant of the loneliness scale showed elevated generalized sensitivity to rejection. Thus, Study 2 confirmed the findings from Study 1 that lonely children have a tendency to expect, perceive and overreact to possible rejection. Depression was included in the analyses and did not explain this bias.

In Study 3, we examine the HSTH for loneliness using eye-tracking technology. Specifically, we examine whether the attention deployment strategies of lonely children are different to non-lonely children. To support the HSTH for loneliness, we would need to find evidence of an attention strategy used by lonely children that matched an attention strategy that was illustrative of hypervigilance.

\section{Study 3}

\section{Method}


Running Head: LONELINESS AND HYPERVIGILANCE TO SOCIAL THREAT

Participants. The participants were 140 children (71 boys and 69 girls) enrolled in Years 5-7 in five primary and two secondary schools in the North West of England, UK. In line with studies 1 and 2, we ensured that these schools were representative of schools in different areas of the UK as determined by the Government Index of Multiple Deprivation. The mean age of participants was 10 years 3 months (age range $=8$ years -10 months to 12 years -10 months, $\mathrm{SD}=6$ months). Active consent for participation had been obtained by the parents/guardians of the children.

\section{Measures}

Loneliness. This was assessed using items from the Peer subscale of the Loneliness and Aloneness Scale for Children and Adolescents (LACA: Marcoen, Goossens, \& Caes, 1987) as detailed in Study 2. Mean scores were used in the analyses. Internal consistency of the pure loneliness scale for the sample in Study 3 was acceptable, $\alpha=.85$.

Depressive symptoms. As in Studies 1 and 2, the 10-item Children's Depression Inventory (CDI: Kovacs, 1992) was used to assess depressive symptoms. Internal consistency for the current sample was good, $\alpha=.92$.

\section{Eye-tracking paradigm.}

This task involved presentation of video footage of social scenes from school playgrounds and lunch-halls that included positive and negative social interaction. The video footage was taken at two primary and secondary schools in a different area of the North of England, ensuring that children in the main study were not watching footage of friends or relatives. Parents or guardians gave active consent for the recording of the playground footage.

Scenes of playground behaviour that could be used as stimuli were systematically rated for social threat in two pilot studies. Participants in these pilot studies (119 undergraduate students [age range: 18-56 years; 75 females; 44 males]; 129 children [age range: aged 8-14 years; 86 females; 43 males]) were asked to rate whether each of the 36 scenes included an example of ‘rejection’ using a 5-point scale of rejection (includes a good example of peer rejection [1] to not a good example [5]). Scenes that ranged from 1-2 on rejection for both samples were chosen for use in the current study. 
Running Head: LONELINESS AND HYPERVIGILANCE TO SOCIAL THREAT

In Study 3, the video footage consisted of eight clips that were shown in a single data collection. In each session, the child watched the eight clips (each approximately 20 seconds in length) during which eye-tracking software was used to measure patterns of visual fixation and scanning. The eight scenes included embedded dyads or small cliques. Although each scene was chosen because it included socially threatening behaviour (interruptions, lack of smiling, discordant body postures and behaviour, lone individual that gets rejected from group), all clips also contained some level of 'positive' conversational behaviour (support of speaker, i.e., nods, encouragement to continue, body posture and gesture mimicking, smiling) between at least one other dyad/clique.

\section{Eye-tracking system.}

An eye-tracking device was used to track the eye movement and the foveal fixation. The eye-tracking device used was an iView X HED model with a dual ocular recording at 200 Hz. The recording was done in stereo bi-ocular recording for optimal precision within SMI BeGaze Video software for HED. Thus, we were able to follow precisely the eye movements of each participant. Because the stimuli included dynamic social scenes, areas of interest were identified and monitored in Observer XT. These areas of interest could not be monitored in the eye-tracking software as is standard in previous papers as they were dynamic and changeable in line with the movements of individuals in the video footage; the use of Observer XT allowed us to monitor the areas of interest and merge this time-line data with the eye-gaze information from the eye-tracker. These areas of interest were (1) threatening stimuli: individual in rejecting group/dyad or person being rejected, and (2) non-threatening stimuli: individual(s) not in the rejecting group. Attention was operationalized in terms of eye fixations. An eye fixation was recorded whenever the participant stopped or had a saccade in one of the two areas of interest. Average glance time was the average amount of time spent during such fixations. To investigate patterns of attention over time, we used time-blocks to examine the proportion of time fixating on the social threat stimuli relative to the total captured glance time for each time block. The use of time-blocks is recommended in the literature looking at attention in eye-tracking studies 
Running Head: LONELINESS AND HYPERVIGILANCE TO SOCIAL THREAT

(Hermans et al., 1999). Because the social threat was happening on screen at the first moment of viewing, we ensured we captured initial vigilance, then any avoidant patterns of visual attention that may be evident amongst lonely children within the first 4 seconds of viewing time. We also examined whether the pattern of attention changed over the full 20 seconds of viewing time.

\section{Procedure.}

After completing the loneliness and depression measures, each participant in turn was escorted to the eye-tracker room set up in the school to complete the experiment. Participants were positioned $60 \mathrm{~cm}$ from the 15-inch laptop display with a 1024 x 768 pixels resolution. Each participant completed the standard calibration procedure. The eight clips were then shown to the participant who was asked to watch the monitor as if they were watching television. After each video clip, a central fixation cross was shown for 1000ms in order to catch the participant's attention. Recording of eye-movement was made in the eye-tracking software, which was then synchronized with the areas of interest data coded within Observer XT.

\section{Results}

For study 3, we first examined the association between loneliness and attention to social threat stimuli using curvilinear analyses. Because of the large age-range in Study 3, we also examined whether there were any developmental effects on attention to the social threat stimuli. We split our sample into a younger age group (YG: 8 years 10 months to $10 \frac{1}{12}$ years, $N=93$ ) and an older age group (OG: 10 years 7 months -12 years 10 months, $N=47$ ). The residual of loneliness was created for both age groups by regressing depression onto loneliness; this new variable acted as the IV in these analyses. Using the residual of loneliness meant we were able to control for depression in our analyses. In our curvilinear analyses, the percentage of fixation time on the threatening stimuli across the 8 time intervals ending at 500ms, $1000 \mathrm{~ms}, 1500 \mathrm{~ms}$, 2000ms, 2500ms, 3000ms, 35000ms, and 4000ms) were the DVs. As stated earlier, where any curvilinear effects are evident, this is with the linear effect controlled. Analyses for both age groups showed significant linear relations for loneliness across all time intervals $\beta \mathrm{s} \geq 1.37$, ps $<.01$, and quadratic relations, $\beta \mathrm{s} \geq 1.40, p s<.01$. 
Running Head: LONELINESS AND HYPERVIGILANCE TO SOCIAL THREAT

To further examine these results for each age group and establish whether attention to the social threat stimuli was biased in lonely children, who were in the upper quadrant of loneliness scores, we used two 2 (group: lonely versus non-lonely) x 8 (time interval, ending at 500ms, 1000ms, 1500ms, 2000ms, 2500ms, 3000ms, 3500ms, and 4000ms) mixed MANCOVAs, controlling for depressive symptoms; one MANCOVA looked at the younger age group (YG) and the other examined changes in attention to social threat stimuli for older children (OG). The results showed a main effect of time for both age groups (YG: $F[\mathrm{df}=7,85]=41.02, p=.001$; OG: $F[\mathrm{df}=7,39]=85.00, p=.001)$, and a main effect of lonely group $(\mathrm{YG}: F[\mathrm{df}=1,91]=$ 25.52, $p=.001$; OG: $F[\mathrm{df}=1,39]=31.43, p=.001$ ). Further, there was a time $\mathrm{x}$ depressive symptom interaction for both age groups (YG: $F[\mathrm{df}=7,85]=3.53, p=.004$; OG: $F[\mathrm{df}=7,39]$ $=4.23, p=.001$ ), and a time $\mathrm{x}$ lonely group interaction (YG: $F[\mathrm{df}=7,85]=5.63, p=.001$; OG: $F[\mathrm{df}=7,39]=6.34, p=.001)$. The time course of attention to the threatening stimuli was different for lonely and non-lonely children from both age groups. Post-hoc testing revealed that in the first second, lonely and non-lonely children are no different in the amount of time they spend looking at the threatening stimuli (YG: $F=1.60, p=.209$ : OG: $F=2.60, p=.114$ ). However, after this, the lonely groups in both age groups differ, with lonely children spending significantly more time than non-lonely children on the threatening stimuli (YG: Fs $>4.14$, ps < .001: OG: Fs $>5.95$, ps < .019). The means for the full sample are presented in Figure 1. They show that lonely children have difficulty disengaging from the threatening stimuli.

We also examined attention patterns of lonely and non-lonely children over the full viewing time by dividing each 20 -second clip into four 5-second segments. Again, we explored whether the pattern of effects was similar for the two age groups. Curvilinear analyses showed quadratic associations between loneliness and attention to social threat stimuli over the full viewing time for both age groups, $\beta \mathrm{s} \geq 1.03, p s<.029$. We extended our analyses using a series of ANCOVAs to examine differences between lonely and non-lonely children in both age groups, when loneliness was defined by membership in the upper quadrant of the loneliness score. The DVs were the percentage of fixation time on the threatening stimuli during each of the four 5-second segments that made up on the full viewing time. ANCOVAs revealed 
Running Head: LONELINESS AND HYPERVIGILANCE TO SOCIAL THREAT

differences between the lonely and non-lonely groups for the three time segments up to 15 seconds for both age groups (YG: Fs [dfs 1, 92] > 4.63, ps <.034; OG: Fs [dfs 1, 47] > 5.03, ps $<.030$ ), but not for the last 5 seconds of viewing time (YG: $F[\mathrm{df} 1,92]=.28, p=.597$; OG: $F$ [df 1,47$]=1.99, p=.165$ ). Lonely children in the current sample up to the age of 12 years had difficulty disengaging from social threat stimuli over the full 20-second viewing time where rejecting social scenes were presented. Figure 2 shows the means for non-lonely and lonely groups within the whole sample across the four 5 -second segments of viewing time.

Time to first fixation on threat stimuli. Curvilinear analysis examining the relations between loneliness and time to fixate on the threat stimuli did not show linear or quadrant effects for either the younger or older age groups (linear and quadratic $\beta \mathrm{s} \leq .41$ and 1.02 respectively). Thus, loneliness was not associated with the time taken to fixate on the threatening stimuli.

\section{Conclusion}

The findings provide support for HSTH. We found (1) all individuals, regardless of loneliness levels, initially attend to stimuli perceived as dangerous (Mogg \& Bradley, 1998), and (2) evidence that lonely children in the upper quadrant of the loneliness scores had difficulties disengaging from the threat stimuli. This same pattern of attention processing was evident for children aged 8-12 years of age.

\section{Discussion}

The relation between loneliness and measures of hypervigilance for social threat was highly similar across the three studies. There was considerable similarity in quadratic curve between loneliness and hypervigilance to social threat as assessed by hostility to ambiguously motivated social exclusion provocation in Study 1, generalized rejection sensitivity in Study 2, and attention towards socially threatening stimuli in Study 3. These findings extend Cacioppo and Hawkley’s (2009) model of loneliness to include children: cognitive biases towards social threat, specifically rejection stimuli, are related to loneliness and are evident early in development. We speculate that these biases in information processing influence behaviour, such that the lonely child becomes withdrawn, distrusting and fearful of negative 
Running Head: LONELINESS AND HYPERVIGILANCE TO SOCIAL THREAT evaluation (Cacioppo et al., 2006; Qualter \& Munn, 2002; Rotenberg, 2010).

The similarities across the three studies yield support for the conclusion that this pattern is durable across samples and measures for children. The different methodologies show that loneliness is associated with hostility to a very specific form of provocation (i.e., social exclusion), but also associated with general rejection sensitivity. Study 3 shows that lonely children exhibit slower disengagement from socially threatening stimuli. The findings from all three studies were obtained when depressive symptoms were statistically covaried, thus helping to rule out the potential for that construct as an account of the observed relations. The finding in Study 1 that the association between loneliness and hostility was unique to ambiguously motivated social exclusion further assists in ruling out negative person perception accounts of the observed relation.

The research addressed the issue of severity of loneliness. This was examined by testing for, and finding, a curvilinear relation between loneliness and hostility to ambiguously motivated social exclusion, generalized rejection sensitivity, and attention deployment strategies when viewing socially threatening stimuli. The precise cut-off point varied between the studies because the specific loneliness scale items varied. Nevertheless, the studies converge in showing that children whose loneliness scores were in the upper quadrant of the distribution show hypersensitivity to social threat. Those children showed a distinctive pattern of social functioning and attentional bias than did other children.

One of the interesting patterns emerging from Study 1 was the negative correlation between loneliness and hostility towards hostilely motivated physical and verbal peer provocation. When taken in the context of the other relations, a rather paradoxical pattern of finding emerges: lonely children appear to be inclined to show hostility towards indirect forms of peer provocation (social exclusion), but appear not to be inclined to show hostility towards direct forms of provocation, such as physical and verbal provocation, which were hostilely intended. Direct forms of provocation are usually more likely to elicit negative reactions from children than are indirect forms of provocation (see Card, Stucky, Sawalani, \& Little, 2008), but lonely children do not appear to follow this same pattern of responding; this probably reflects 
Running Head: LONELINESS AND HYPERVIGILANCE TO SOCIAL THREAT

the importance of this type of provocation for lonely children, which supports findings from the adult HSTH work showing that fears of social exclusion are characteristic of lonely people.

Moreover, lonely children's negative response to this perceived social exclusion highlights how the negative social expectations of lonely people can elicit behaviours that increase the likelihood that they will actually be rejected by the people they want to engage with.

Based on Study 1 findings, there appear to be similarities and differences between very lonely and aggressive children in their reactions to peer provocation. Similar to aggressive children, very lonely children are prone to attribute hostile intentions to ambiguously motivated peer provocation and engage in retaliatory aggression as a reaction to it (see Orobio de Castro et al., 2002). Nevertheless, very lonely children demonstrate those patterns solely as reactions to social exclusion, which highlights that those likely arise from their sensitivity to social rejection.

Our findings also show that lonely children have difficulty disengaging attention from socially threatening stimuli. Literature on anxiety suggests that this inability to disengage from threat cues plays an important part in the maintenance of anxiety disorder (Fox et al., 2001); our findings suggest that this may also be the case for loneliness. For social anxiety, specifically, disengagement difficulties have been linked to rumination of negative social events, which encourages the activation of memories associated with negative social evaluation or negative social experiences (Buckner et al., 2010). Further, Buckner et al note that disengagement difficulties in social anxiety lead to social problems because people fail to understand social threat cues in context (i.e., facial expressions are often viewed without being linked to the environmental cues that they are associated with). Thus, it is possible that the disengagement difficulties shown by lonely children explain (1) their tendency to ruminate on negative emotions (Vanhalst et al., 2012), and (2) their problems in social relationships despite the fact that they often have good social skills (Qualter \& Munn, 2005).

Implications for interventions. There are clear implications of our findings for intervention. The findings suggest that attribution and attention retraining might help lonely children. The finding that the disengagement difficulties are evident from age 8 years suggests that early intervention is warranted. Also, the findings suggest there is something unique about 
Running Head: LONELINESS AND HYPERVIGILANCE TO SOCIAL THREAT those very high on loneliness suggesting that it is these children who would benefit from intervention. Future work will want to do more work with this very lonely group to determine whether they also vary from non-lonely children on other behaviours, perceptions, and psychopathologies.

Limitations and Directions for Future Research. There are some limitations regarding the current findings, which will have implications for future work. First, data in studies 1 and 2 were gathered by children's responses to hypothetical scenarios, which rely on children's explicit recognition and reporting of often-unconscious processes (Orobio de Castro et al., 2002; Vitaro \& Pelletier, 1991). Studies 1 and 2 also use self-reports of loneliness, depressive symptoms, and cognitions, which could have resulted in the problem of shared method variance. In an attempt to over come these problems, in Study 3 we examined the HSTH using eye-tracking techniques. However, the use of other methodologies is important, and future work should observe how children behaviourally react to possible social threat from peers in naturalistic situations. In this vein, it is worthwhile noting that children's responses to hypothetical scenarios assessing the hostility attribution bias are consistent with behavioral observations of the children’s peer interactions (e.g., Dodge, 1980; Dodge \& Somberg, 1987); the similar curvilinear relationships found across our three studies further support this.

Second, the current research addressed whether lonely children were hypersensitive to social threat in peer groups. The HSTH does not prescribe that the hypervigilance to social threat by lonely children resides in their reactions to peers only, and future work should explore the HSTH in relationships outside of the peer context.

Third, our findings from study 3 show a pattern of attentional bias to social threat stimuli consistent with findings for socially anxious older adolescents (i.e., Buckner et al., 2010). Although previous research with adults has shown that social anxiety and loneliness are distinct construct (Johnson, LaVoie, \& Mahoney, 2001; Jones et al., 1990), some research with children suggests that the two concepts are associated (Weeks, Coplan, \& Kingsbury, 2009). Thus, in future studies, researchers should examine the exact association between social anxiety and 
Running Head: LONELINESS AND HYPERVIGILANCE TO SOCIAL THREAT

loneliness in childhood and adolescence and investigate how each of these impacts on social information processing in the same sample.

Study 3 was the first examination of the HSTH using eye-tracking methodologies; similar work has not be conducted using adolescent or adult samples and future work will want to examine the attention deployment patterns of lonely versus non-lonely individuals in these groups. Because the ability to control attention remains immature until developments in mid to late adolescents (Anderson et al., 2001), the pattern of poor disengagement found in Study 3 may be characteristic of lonely children and adolescents only; this same pattern of viewing behaviour may not be evident amongst adults whose cognitive skills are more developed (see Puliafico, \& Kendall, 2006). Thus, future research should examine the attention biases of lonely adolescents and adults to determine whether there are any changes in attention bias due to cognitive maturity. Further, in Study 3, we used video clips that had been rated as excellent examples of rejecting stimuli, but future work should investigate whether similar disengagement difficulties are evident when stimuli depicting mild or moderate social threat are used.

The use of cross-sectional data is also a limitation of the studies. Cacioppo and Hawkley's (2009) model is not explicit about whether loneliness triggers cognitions linked to rejection sensitivity or whether they are in place first. Our data show that threat-related cognitions are evident for loneliness in middle to late childhood; the next steps are to examine how these cognitions relate to the stability of loneliness, and investigate the direction of these relationships over time. This future prospective work will inform whether interventions for lonely children should target these cognitive biases in order to reduce persistent loneliness or whether targeting these cognitive bias could stop loneliness occurring in the first place.

Despite the limitations, the present study is the first to provide evidence for the HSH for loneliness in childhood. Although different methods and measures were employed in the three studies, they yielded complementary findings lending support for the robustness of the phenomena. We extend Cacioppo and Hawkley's (2009) model of loneliness to include children and show that threat-related cognitions and attention to social threat, specifically threats around social exclusion and rejection, are associated with loneliness in childhood. 
Running Head: LONELINESS AND HYPERVIGILANCE TO SOCIAL THREAT

\section{References}

Anderson, V.A., Anderson, P., Northam, E., Jacobs, R., \& Catroppa, C. (2001). Development of executive functions through late childhood and adolescence in an Australian sample. Developmental Neuropsychology, 20, 385-406.

Asher, S. R., Hymel, S., \& Renshaw, P. D. (1984). Loneliness in children. Child Development, 55, 1456-1464.

Baumeister, R. F., DeWall, C. N., Ciarocco, N. J., \& Twenge, J. M. (2005). Social Exclusion Impairs Self-regulation. Journal of Personality and Social Psychology, 88, 589-604.

Baumeister, R.F., \& Leary, M.R. (1995). The need to belong: Desire for interpersonal attachments as a fundamental human motivation. Psychological Bulletin, 117, 497-529.

Boivin, M., Poulin, F., \& Vitaro, F. (1994). Depressed mood and peer rejection in childhood. Development and Psychopathology, 6, 483-498.

Buckner, J.D., Maner, J.K., \& Schmidt, N.B. (2010). Difficulty disengaging attention from social threat in social anxiety. Cognitive Therapy Research, 34, 99-105.

Cacioppo, J.T., Ernst, J. M., Burleston, M. H., McClintock, M. K., Malarkey, W. B., Hawkley, L. C., Kowalewski, R. B., Paulsen, A., Hobson, A., Hugdahl, K., Spiegel, D., \& Bernston, G. G. (2000). Lonely traits and concomitant physiological processes: the MacArthur social neuroscience studies. International Journal of Psychophysiology, 35, 143-154.

Cacioppo, J.T. \& Hawkley, L.C. (2009). Perceived social isolation and cognition. Trends in Cognitive Science, $13,447-454$.

Cacioppo, J. T., Hawkley, L. C., Ernst, J. M., Burleson, M., Berntson, G. G., Nouriani, B., \& Spiegel, D., (2006). Loneliness within a nomological net: An evolutionary perspective. Journal of Research in Personality, 40, 1054-1085.

Cacioppo, J.T., Norris, C.J., Deacety, J., Monteleone, G., \& Nusbaum, H. (2009). In the eye of the beholder: Individual differences in perceived social isolation predict regional brain activation to social stimuli. Journal of Cognitive Neuroscience, 21, 83-92.

Cacioppo J. T, Patrick W (2008) Loneliness: Human Nature and the Need for Social Connection. W.W. Norton and Company, London. 
Running Head: LONELINESS AND HYPERVIGILANCE TO SOCIAL THREAT

Card N. A., Stucky B. D., Sawalani, G. M., \& Little T. D. (2008). Direct and indirect aggression during childhood and adolescence: a meta-analytic review of gender differences, intercorrelations, and relations to maladjustment. Child Development, 79, 1185-229.

Cohen, J., Cohen, P., West, S. G., \& Aiken, L. S. (2003). Applied multiple regression/correlation analysis for the behavioral sciences ( $3^{\text {rd }}$ ed). Mahawah, New Jersey, Lawrence Erlbaum.

Dineen, K.A., \& Hadwin, J.A. (2004). Anxious and depressive symptoms and children’s judgements of their own and others' interpretation of ambiguous social scenarios. Journal of Anxiety Disorders, 18, 499-513.

Doane, L. H. \& Adam, E. K. (2010). Loneliness and cortisol: Momentary, day-to-day, and trait associations. Psychoneuroendocriniology, 35, 430-441.

Dodge, K. A. (1980). Social cognition and children’s aggressive behavior. Child Development, 51, 162-170.

Dodge, K. A., \& Somberg, D. R. (1987). Hostile attributional biases among aggressive boys are exacerbated under conditions of threats to the self. Child Development. 58, 213-224.

Downey, G., Lebolt, A., Rincon, C., \& Freitas, A. (1998). Rejection sensitivity and children’s interpersonal difficulties. Child Development, 69, 1074-1091.

Duck, S., Pond, K., Leatham, G. (1994). Loneliness and the Evaluation of Relational Events. Journal of Social and Personal Relationships, 11, 253-276.

Fox, E., Russo, R., Bowles, R., \& Dutton, K. (2001). Do threatening social stimuli draw or hold visual attention in subclinical anxiety? Journal of Experimental Psychology, 130, $681-700$

Gardner, W.L., Pickett, C.L., Jefferis, V., \& Knowles, M. (2005). On the outside looking in: Loneliness and social monitoring. Personality and Social Psychology Bulletin, 31, 15491560. 
Running Head: LONELINESS AND HYPERVIGILANCE TO SOCIAL THREAT

Hawkley, L. C. \& Cacioppo, J. T. (2010). Loneliness matters: A theoretical and empirical review of consequences and mechanisms, Annals of Behavioral Medicine, 40, 218-227.

Hawkley, L. C., Burleson, M. H., Berntson, G. G., \& Cacioppo, J. T. (2003). Loneliness in everyday life: Cardiovascular activity, psychosocial context, and health behaviors. Journal of Personality and Social Psychology, 85, 105-120.

Heinrich, L.M., \& Gullone, E. (2006). The clinical significance of loneliness: A literature review. Clinical Psychology Review, 26, 695-718.

In-Albon, T., Kossowsky, J., \& Schneider, S. (2010). Vigilance and avoidance of threat in the eye movements of children with separation anxiety disorder. Journal of Abnormal Child Psychology, 38, 225-235.

Jobe-Shields, L., Cohen, R., \& Parra, G. (2011). Patterns of Change in Children’s Loneliness: Trajectories from Third Through Fifth Grades. Merrill Palmer Quarterly, 57, 25-47.

Johnson, H. D., LaVoie, J. C., \& Mahoney, M. (2001). Interparental conflict and family cohesion predictors of loneliness, social anxiety, and social avoidance in late adolescence. Journal of Adolescent Research, 16, 304-318.

Jones, A. C., Schinka K. C., van Dulmen, M. H. M , Bossarte R. M. \& Swahn M. H. (2011). Changes in Loneliness during Middle Childhood Predict Risk for Adolescent Suicidality Indirectly through Mental Health Problems. Journal of Clinical Child \& Adolescent Psychology, 40, 818-824.

Jones, W. H. (1990). Loneliness and social exclusion. Journal of Social \& Clinical Psychology, 9, 214-220.

Jones, W. H., \& Carver, M. D. (1991). Adjustment and coping implications of loneliness. Handbook of social and clinical psychology: The health perspective.

Jones, W. H., Rose, J., \& Russell, D. W. (1990). Loneliness and social anxiety. Handbook of social and evaluation anxiety. Leitenberg, Harold (Ed); pp. 247-266. New York, NY, US: Plenum Press.

Jones, W.H., Sansone, C., \& Helm, B. (1983). Loneliness and interpersonal judgments. Personality and Social Psychology Bulletin, 9, 437-441. 
Running Head: LONELINESS AND HYPERVIGILANCE TO SOCIAL THREAT

Jones, W. H., Freemon, J. E., \& Goswick, R. A. (1981). The persistence of loneliness: Self and other determinants. Journal of Personality, 49, 27-48.

Kovacs, M. (1992). The children's depressive symptoms inventory manual. New York: Multi Health Systems.

Kovacs, M., \& Beck, A. T. (1977). An empirical clinical approach toward a definition of childhood depressive symptoms. In J. G. Schulterbrandt, \& A.

Ladd, G. W., Kochenderfer, B. J., \& Coleman, C. C. (1997). Classroom peer preference, friendship and victimization: Distinct relational systems that contribute uniquely to children’s school adjustment? Child Development, 68(6), 1181-1197.

Ladd G. W., Kochenderfer B. J., Coleman C. C. (1996). Friendship quality as a predictor of young children's early school adjustment. Child Development, 67, 1103-18.

Lange, W.G., Heuer, K., Langner, O., Keijsers, G.P.J., Becker, E.S., \& Rinck, M. (2011). Face value: Eye movements and the evaluation of facial crowds in social anxiety. Journal of Behavioral Therapy \& Experimental Psychiatry, 42, 355-363.

Lasgaard, M. Goossens, L. \& Elklit, A. (2011). Loneliness, Depressive Symptomatology, and Suicide Ideation in Adolescence: Cross-Sectional and Longitudinal Analyses. Journal of Abnormal Child Psychology, 39, 137-150.

Levy, S., Ayduk, O., \& Downey, G. (2002). The role of rejection sensitivity in people’s relationships with significant others and valued social groups. In M. Leary (Ed.), Interpersonal rejection (pp. 251-289). Oxford, UK: Oxford University Press.

London, B., Downey, G., Bonica, C., \& Paltin, I. (2007). Social causes and consequences of rejection sensitivity. Journal of Research on Adolescence, 17, 481-506.

Luna, B., Garver, K.E., Urban, T.A., Lazar, N.A. \& Sweeney, J.A. (2004). Termperament, anxiety, and the processing if threat-related stimuli. Journal of Clinical Child and Adolescent Psychology, 33, 8-20.

Marcoen A, Goossens L, Caes P (1987) Loneliness in pre through late adolescence: Exploring the contribution of a multidimensional approach. Journal of Youth and Adolescence 16, 561-577. 
Running Head: LONELINESS AND HYPERVIGILANCE TO SOCIAL THREAT

Mogg, K., \& Bradley, B.P., (1998). A cognitive-motivational analysis of anxiety. Behavioural Research and Therapy, 36, 809-848.

Nangle, D. W., Erdley, C. A., Newman, J. E., Mason, C. A., \& Carpenter, E. M. (2003). Popularity, friendship quantity: Interactive influences on children’s loneliness and depression. Journal of Clinical Child and Adolescent Psychology, 32, 546-555.

Orobio de Castro, B., Veerman, J. W., Koops, W., Bosch, J. D., \& Monshouwer, H. J. (2002). Hostile attribution of intent and aggressive behavior: A meta-analysis. Child Development, 73, $916-934$.

Pearson, D.A., \& Lane, D.M. (1991). Visual attention movements: A developmental study. Child Development, 61, 1779-1795.

Peplau, L. \& Perlman, D. (eds.). Loneliness: A Sourcebook of Current Theory, Research and Therapy. New York: John Wiley and Sons.

Puliafico, A.C., \& Kendall, P.C. (2006). Threat-Related Attentional Bias in Anxious Youth: A Review. Clinical Child and Family Psychology Review, 9, 162-180.

Qualter, P., Brown, S.L., Munn, P., \& Rotenberg, K. (2010). Childhood loneliness as a predictor of depression: An 8-year longitudinal study. European Journal of Child and Adolescent Psychiatry, 19, 493-501.

Qualter, P., Brown, S.L., Rotenberg, K.J., Vanhalst, J, Harris, R.A., Goossens, L \& Munn, P. (in press). Trajectories of Loneliness during Childhood and Adolescence: Predictors and health outcomes. Journal of Adolescence: Special Issue on Loneliness.

Qualter, P. \& Munn, P. (2002). The separateness of emotional and social isolation in childhood. Journal of Child Psychology and Psychiatry, 43, 233-244.

Qualter, P. \& Munn, P (2005). The friendships and play partners of lonely children. Journal of Social and Personal Relationships, 22, 379-397.

Quiggle, N. L., Garber, J., Panak, W. F., \& Dodge, K. A. (1992). Social information processing in aggressive and depressed children. Child Development, 63, 1305-1320.

Rotenberg, K. J. \& Hymel, S. (Eds.) (1999). Loneliness in childhood and adolescence. New York: Cambridge University Press. 
Running Head: LONELINESS AND HYPERVIGILANCE TO SOCIAL THREAT

Rotenberg, K. J., Addis, N., Betts, L. R., Fox, C., Hobson, Z., Rennison, S.,Trueman, M. \& Boulton, M. J. (2010). The relation between trust beliefs and loneliness during early childhood, middle childhood and adulthood. Personality and Social Psychology Bulletin, 36, 1086-1100.

Sandstrom, M. J., Cillessen, A. H. N., Eisenhower, A., (2003). Children's appraisal of peer rejection experiences: Impact on social and emotional adjustment. Social Development, 12, 530-550.

Sloan, W., and Solano, C. (1984). The conversational styles of lonely males with strangers and room mates. Personality and Social Psychology Bulletin, 10, 293-301.

Snodgrass, M.A. (1987). The relationship of differential loneliness, intimacy, and characterological attributional style to duration of loneliness. Journal of Social Behavior and Personality, 2, 173186.

Vanhalst, J., Luyckx, K., Raes, F., \& Goosens, L. (2012). Loneliness and Depressive Symptoms: The Mediating and Moderating Role of Uncontrollable Ruminative Thoughts. The Journal of Psychology: Interdisciplinary and Applied, 146, 259-276.

Vitaro, F. \& Pelletier, D. (1991). Assessment of children's social problem-solving skills in hypothetical and actual conflict situations. Journal of Abnormal Child Psychology, 19, 505518.

Weeks, M., Coplan, R. J., \& Kingsbury, A. (2009). The correlates and consequences of early appearing social anxiety in young children. Journal of Anxiety Disorders, 23, 965-972.

Young, J. E. (1982). Loneliness, depression and cognitive therapy: Theory and application. In L. A. Peplau \& D. Perlman (Eds.), Loneliness: A sourcebook of current theory, research and therapy (pp. 379-406). New York: Wiley. 
Running Head: LONELINESS AND HYPERVIGILANCE TO SOCIAL THREAT

Table 1

Study 1: Partial Correlations Among the Measures for Level of Motivation and Type of

Provocation (Means and SDs ) for Attribution of Intention and Retaliation Controlling for

Depressive Symptoms

\begin{tabular}{lcccccccc}
\hline Measure & $M$ & $S D$ & HMP & HMV & HMSE & AMP & AMV & AMSE \\
\hline \multicolumn{7}{c}{ Attribution of Hostile Intention } \\
Loneliness & 4.07 & 3.11 & -.08 & $-.14^{*}$ & -.04 & -.12 & -.09 & $.14^{*}$ \\
Provocation: Hostilely & Motivated (HM) & & & & & \\
Physical (HMP) & 3.95 & 1.21 & .09 & .09 & $.19^{* *}$ & $.18^{*}$ & .04 \\
Verbal (HMV) & 4.27 & .86 & & $.29 * * *$ & .08 & .12 & .06 \\
Social Exclusion & 3.90 & 1.08 & & & $.20^{* *}$ & .11 & $.21^{* *}$ \\
(HMSE) & & & & & & \\
Provocation: Ambiguously Motivated (AM) & & & & & \\
Physical (AMP) & 2.65 & 1.36 & & & & & $.31^{* * *}$ & $.20^{* *}$ \\
Verbal (AMV) & 3.00 & 1.26 & & & & & .10 \\
Social Exclusion & 1.68 & .29 & & & & & \\
(AMSE) & & & & & & &
\end{tabular}

\begin{tabular}{lcccccccc}
\hline \multicolumn{7}{c}{ Retaliation } \\
\hline Loneliness & 4.07 & 3.11 & .15 & $-.10^{*}$ & -.03 & -.16 & -.02 & $.20^{* *}$ \\
Provocation: Hostilely Motivated (HM) & & & & & \\
Physical (HMP) & 3.22 & 1.35 & & $.62^{* * *}$ & $.39^{* * *}$ & $.57^{* * *}$ & $.18^{* * *}$ & $.27^{* * *}$ \\
Verbal (HMV) & 3.20 & 1.25 & & $.48^{* * *}$ & $.52^{* * *}$ & $.59^{* * *}$ & $.30^{* * *}$ \\
Social Exclusion & 2.93 & 1.30 & & & $.34^{* *}$ & $.33^{* * *}$ & $.44^{* *}$ \\
(HMSE) & & & & & & \\
Provocation: Ambiguously & Motivated (AM) & & & & & \\
Physical (AMP) & 2.62 & 1.38 & & & & $.43^{* * *}$ & $.35^{* *}$ \\
Verbal (AMV) & 2.34 & 1.30 & & & & $.22^{* *}$ \\
Social Exclusion & 1.89 & 1.03 & & & & \\
(AMSE) & & & & & & & \\
\hline
\end{tabular}

Note: $d f s=181 .{ }^{*} p<.05,{ }^{* *} p<.01$ and ${ }^{* * *} p<.001$. 
Running Head: LONELINESS AND HYPERVIGILANCE TO SOCIAL THREAT

\section{Table 2}

Study 1: Partial Correlations Among the Measures by Motivation and Type of Provocation for

Hostility (with Means and Standard Deviations) Controlling for Depressive Symptoms

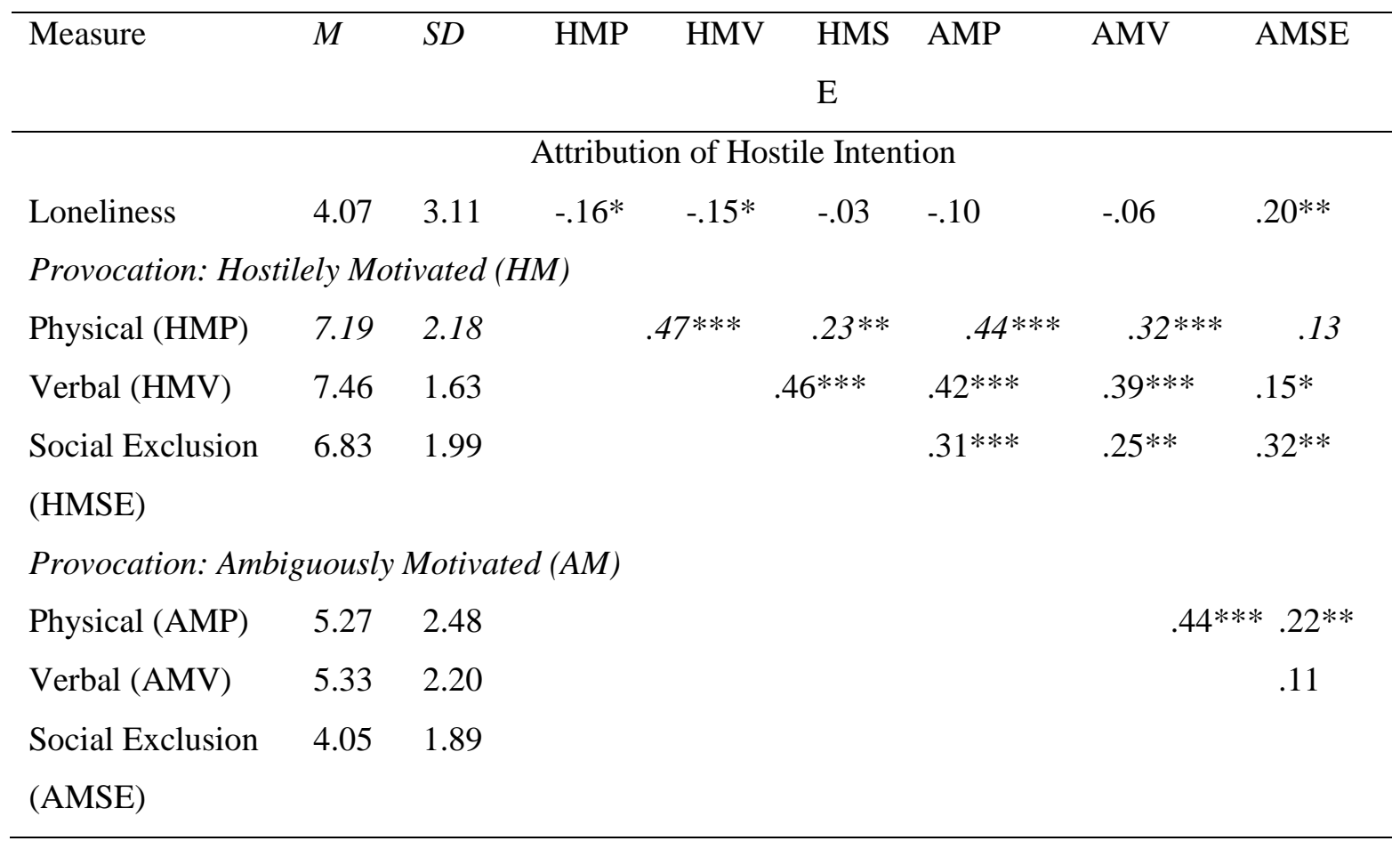

Note: $d f s=181 .{ }^{*} p \leq .05,{ }^{* *} p<.01$ and ${ }^{* * *} p<.001$. 
Figure 1. Mean proportion of fixation time during the first four seconds on socially threatening stimuli by loneliness.

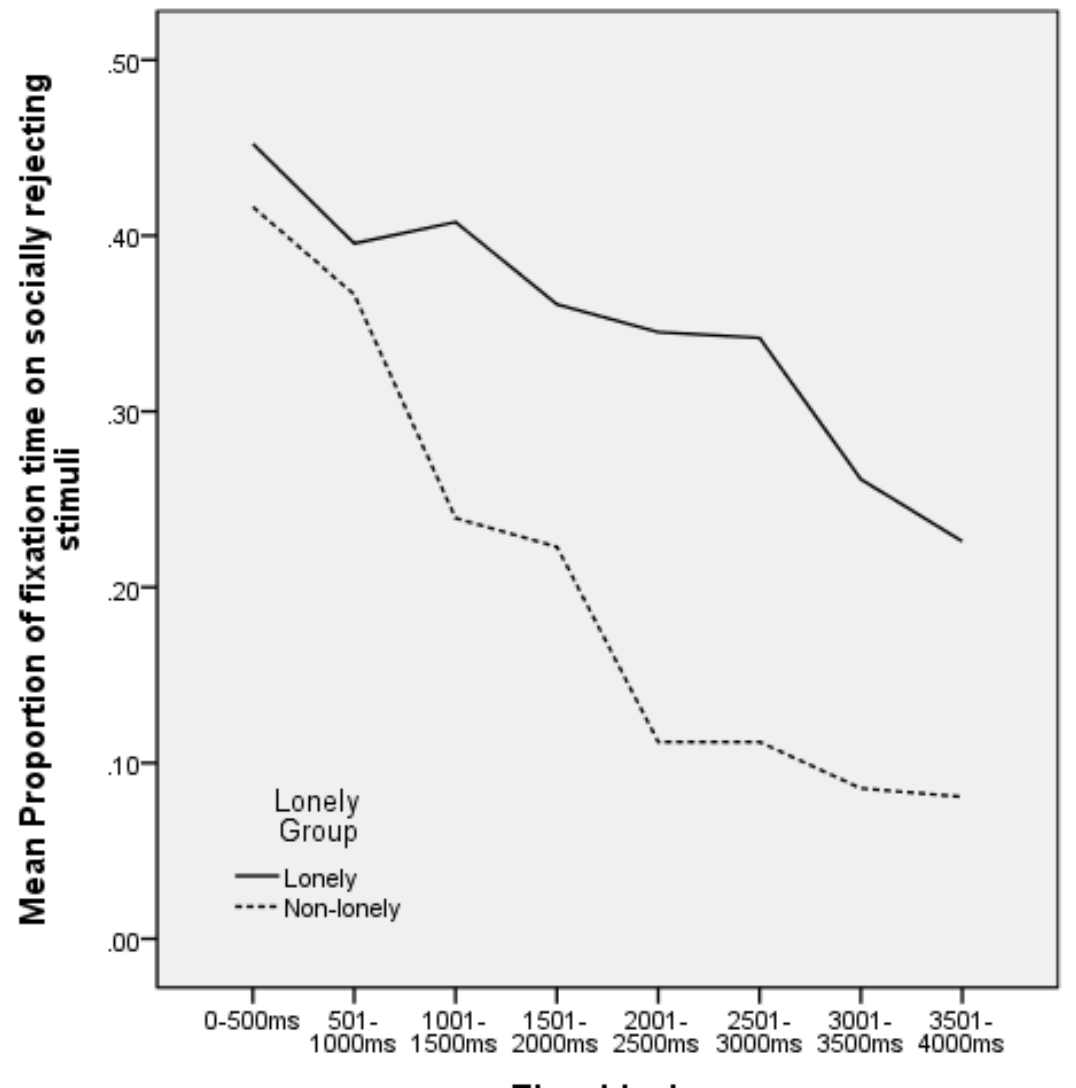

Time blocks

Notes: Data presented here is for the full sample of children aged 8-12 years; the same pattern was found for children aged 8 years -10 years 6 months and 10 years 7 months - 12 years.

High lonely children were those that scored in the upper quadrant of the 'pure' loneliness measure. Post-hoc tests showed that the groups do not differ in the first second. However, after that, lonely children spent significantly more time than non-lonely children on the threatening stimuli. 
Running Head: LONELINESS AND HYPERVIGILANCE TO SOCIAL THREAT

Figure 2. Mean proportion of fixation time during the full viewing time on socially threatening stimuli by loneliness.

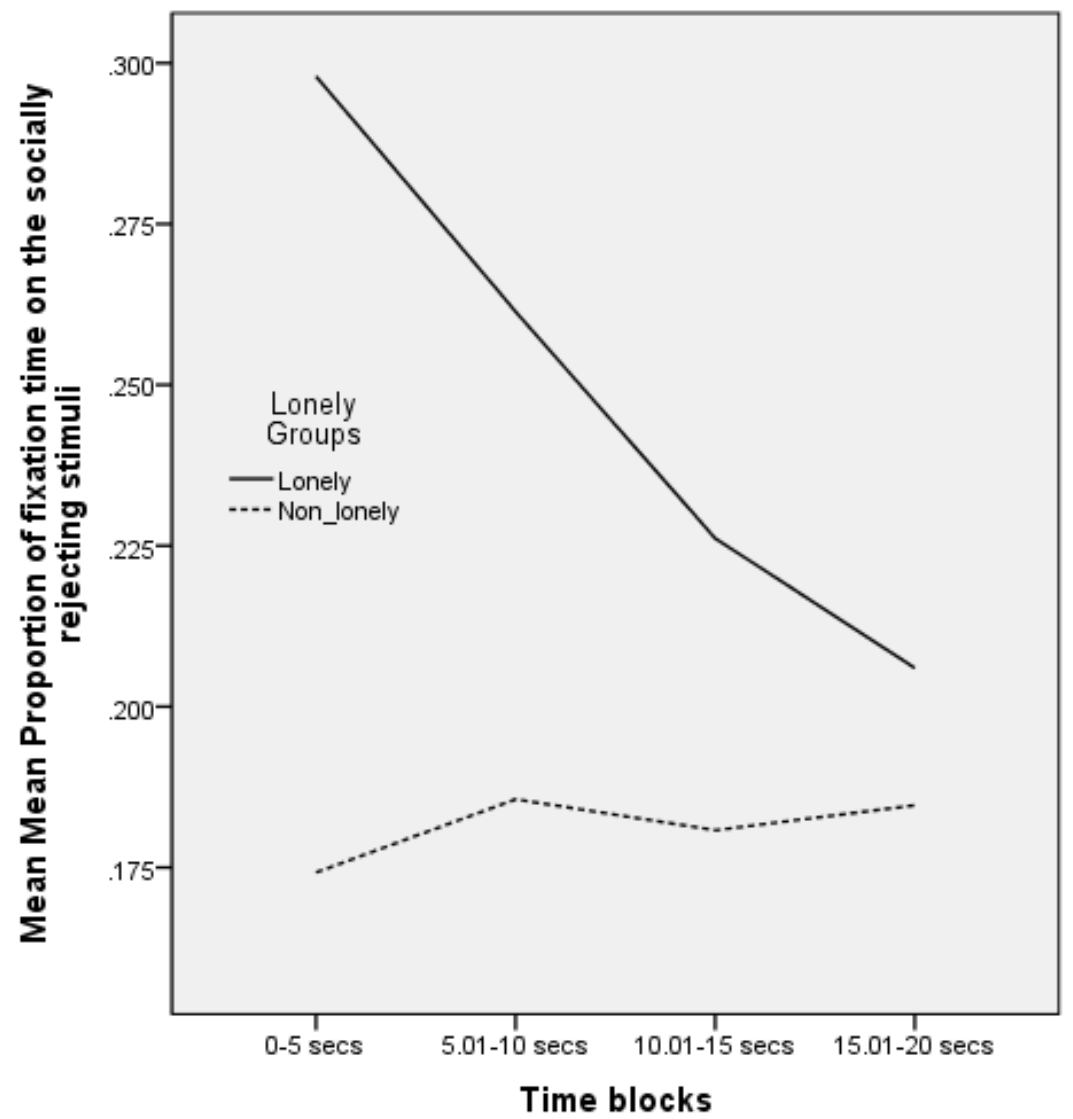

Notes: Data presented here is for the full sample of children aged 8-12 years; the same pattern was found for children aged 8 years -10 years 6 months and 10 years 7 months -12 years. High lonely children were those that scored in the upper quadrant of the 'pure' loneliness measure. Post-hoc tests showed that lonely children were significantly different to non-lonely children in their viewing of the social threat stimuli for the first 15 seconds of viewing time; lonely and non-lonely children were no different during the final time block (15.01-20 seconds). 